\title{
INTERFACES PARA SOFTWARES EDUCATIVOS
}

\author{
Eliseo Reategui*
}

\begin{abstract}
Resumo. Por que a leitura de um livro bem encadernado, com boa diagramação e repleto de ilustrações coloridas provê uma leitura mais prazerosa e até nos permite lembrar mais informações do que se lêssemos o mesmo material em um livro mais modesto sem nenhuma preocupação com formatação? Este artigo responde esta pergunta através da discussão de como a utilização de imagens, a apresentação de textos, o layout de página e outros fatores afetam a interface de um sistema computacional, do mesmo modo que afetam a construção de um bom livro. Aspectos pedagógicos relativos à concepção das interfaces também são destacados, mostrando como estes norteiam o design dos sistemas para promover o pensamento, a reflexão e conseqüentemente, a aprendizagem.
\end{abstract}

Palavras-chave: interface humano-computador, usabilidade, softwares educativos

\section{INTERFACES FOR EDUCATIONAL SOFTWARE}

\begin{abstract}
Why does the reading of a book with a nice cover, with well presented contents and illustrations promote a more pleasurable reading and even enables us to remember more information than if we read the same material in a less fancy book? This article answers this question through the discussion on how the use of images, the presentation of texts, the design of page layouts and other factors affect the interface of a computational system in the same way they affect the creation of a good book. Pedagogical aspects related to interface design are also highlighted, showing how they guide system design in order to promote thinking, reflection and, consequently, learning.
\end{abstract}

Keywords: human-computer interface, usability, educational software

\section{Introdução}

A distância entre as expectativas geradas pelo uso de tecnologia na educação e a realidade dos próprios softwares disponíveis é uma constante nos dias de hoje (Resnick, 2002). Tal distância é muitas vezes é ocasionada não apenas pela concepção dos softwares e de suas funcionalidades, mas também pelo design simplista das interfaces e de seus processos interativos. Uma interface atraente com dispositivos de interação adequados tem um efeito positivo na usabilidade do software, em sua aceitação, bem como no seu potencial para promoção da aprendizagem. Por isso a concepção do software e de sua interface deve estar alinhada a princípios pedagógicos adequados, atendendo desde requisitos como formato de apresentação de conteúdo e interação, até a quantidade de informação apresentada.

Este artigo decompõe a interface de um software educativo em oito aspectos e apresenta algumas diretrizes de como projetar adequadamente cada um deles. Interação,

\footnotetext{
* Doutor em Computação. Professor Adjunto do Departamento de Informática - Universidade de Caxias do Sul (UCS). Rua Francisco Getúlio Vargas, 1130 - 95070-560 Caxias do Sul - RS. E-mail: ebreateg@ucs.br
} 
usabilidade e afetividade são alguns dos tópicos tratados, relacionando-os com princípios pedagógicos fundamentais na concepção destes softwares.

\section{Utilização de imagens e animações}

Shimada e Kitajima (2006) apontam dois fatores que fazem com que ilustrações tenham um impacto positivo na aprendizagem:

- Efeito de motivação: este é caracterizado pelo impulso que temos em realizar ou não uma ação. Uma ilustração pode, por exemplo, nos motivar a ler um texto ou nos levar a ignorá-lo.

- Efeito de elaboração: quando um indivíduo visualiza uma imagem junto a um texto, este cria uma representação da imagem e a associa ao conteúdo lido. O processo é chamado de efeito de elaboração.

Ambos os fatores influenciam positivamente na construção do conhecimento. Mayer e Moreno (2007) também evidenciam a importância das imagens na compreensão de textos. Os autores apontam que, de acordo com o princípio da representação múltipla, é melhor apresentar uma explicação através de textos e ilustrações do que apenas através de textos. Em uma série de experimentos, verificou-se que estudantes que ouviram uma narração enquanto visualizavam uma animação ilustrando o funcionamento de uma bomba de pneu foram capazes de produzir mais soluções úteis em testes subseqüentes do que os estudantes que apenas ouviram a narração (Mayer e Anderson, 1992).

O poder explicativo das imagens, no entanto, está associado à forma com que estas são empregadas. Meyer (2001) aponta que imagens podem ser utilizadas com diferentes funções:

- Função decorativa: uma imagem possui a função decorativa quando tem o propósito de melhorar a aparência estética do material no qual está inserida. Portanto, as imagens utilizadas desta maneira não carregam nelas nenhuma mensagem diretamente ligada aos conteúdos tratados.

- Função representativa: nesta função, a imagem exemplifica um conceito apresentado textualmente, representando-o através de uma ilustração. Por exemplo, uma descrição textual de determinada planta pode ser ilustrado por uma imagem representativa do vegetal.

- Função organizacional: as imagens empregadas com a função organizacional ilustram relações entre conceitos ou entre elementos que compõem determinado objeto. Por exemplo, uma imagem com função organizacional pode ilustrar a disposição dos diversos componentes do motor de um automóvel.

- Função explanatória: nesta função, as imagens explicam como é o funcionamento de um sistema dinâmico, no qual a variável tempo é considerada. Por exemplo, a imagem anterior que apresentava o motor de um automóvel pode assumir a função explanatória se a dotarmos de setas indicando como é o funcionamento dos pistons do automóvel quando o motor é ativado.

Por não carregarem nenhuma informação explícita em suas representações gráficas, as imagens com função decorativa acabam cumprindo um papel secundário no que diz respeito aos processos de aprendizagem. Contudo, estes não podem ser negligenciados, podendo estar associados a fatores como motivação e usabilidade aparente da interface, princípios discutidos com mais detalhe na seção 8 . 
Já as animações podem ter funções semelhantes àquelas das imagens estáticas. Ou seja, podem ser utilizadas com função decorativa, representativa, organizacional ou explanatória. No entanto, as animações se adequam mais à representação de conceitos e/ou elementos dinâmicos, nos quais mudanças no objeto em estudo são observadas com o passar do tempo (função explanatória).

De acordo com o princípio da congruência, a estrutura e o conteúdo de uma visualização devem corresponder à estrutura e ao conteúdo da representação mental a ser incitada (Tversky, 2007). Princípio estabelecido inicialmente para imagens estáticas, quando estendido às animações poderia ser interpretado da seguinte forma: as animações podem facilitar a aprendizagem na medida em que empregam movimento para representar movimento. No entanto, Morrison e Tversky, B. (2001) mostram que alunos que estudaram determinados conteúdos a partir de textos ilustrados por animações ou imagens estáticas obtiveram desempenho similar. As autoras enfatizam, contudo, que é possível que as animações sejam eficientes em outras situações, especialmente para manter a atenção dos estudantes.

\section{Apresentação de textos}

Nielsen (1997) afirma que não se lê na web da mesma maneira que no meio impresso. Portanto, não se deve escrever para a web do mesmo jeito que para o meio impresso. Em decorrência disso, a apresentação de textos nas telas do computador deve ser feita com alguns cuidados.

Um dos principais motivos pelos quais nossa leitura nas telas dos computadores é diferente, é que a resolução destas ainda é limitada, mesmo que pouco a pouco se aproxime da resolução do papel. Além disso, os monitores têm uma taxa de refresh que pode ser imperceptível ao olho, mas que aos poucos vai o cansando o leitor. Pesquisas também mostram que este pisca menos ao ler em frente a um monitor, causando ressecamento nos olhos.

Portanto, uma interface computacional para apresentação de textos deve seguir algumas recomendações, dentre elas (Bailey et al., 2007):

- Textos na cor preta apresentados sobre fundo neutro permitem uma leitura mais rápida do que quando apresentados sobre um fundo no qual há alguma textura;

- A formatação de itens similares deve ser consistente em todas as seções da interface;

- A utilização de texto em negrito deve ser feita espaçadamente, na medida em que muitos elementos enfatizados em um mesmo texto acabam por perder o efeito.

- As fontes que possibilitam melhor leitura são aquelas mais conhecidas, como Times New Roman e Georgia (fontes com serifa) ou Arial, Helvética e Verdana (fontes sem serifa). Nielsen (2002, pg. 51) complementa enfatizando que aquelas sem serifa deveriam ser preferidas, já que os detalhes das serifas não são bem renderizados nos monitores atuais que possuem baixa resolução. No entanto, o autor destaca que, na medida em que monitores de alta resolução se tornarem comuns, esta recomendação pode mudar. Quanto ao tamanho das fontes, 12pt é tido como o tamanho mais apropriado para leitura na tela. 


\section{Layout de tela}

Nos dias de hoje, somos constantemente bombardeados por uma multitude de estímulos visuais. Nossa mente ignora a maior parte desses, processando apenas aqueles que recebem um significado especial baseado em nossa experiência anterior.

Krug (2002, p.22) aponta que não lemos as páginas na web, mas rastreamos estas em busca de palavras ou frases que capturem nossa atenção. $O$ tamanho, cor e disposição dos elementos na página influenciam a facilidade com que os localizamos. Elementos maiores são encontrados mais rapidamente, bem como elementos em cores saturadas que contrastam com o fundo da tela.

Quanto à disposição destes elementos, no mundo ocidental as pessoas estão habituadas a lerem da esquerda para a direita, de cima para baixo. Tal ordem é obedecida na construção de páginas web, nas quais informações importantes como nomes de empresas e instituições se encontram no canto superior esquerdo das páginas. Se consultarmos páginas web em países onde a leitura de textos é feita na direção contrária, veremos que a orientação dos elementos na tela também é totalmente oposta. Por isso, é interessante obedecer uma ordem no posicionamento das informações que respeite esta norma, ou seja, elementos mais importantes nas porções da tela que são comumente percorridas em primeiro lugar.

Transpondo estas idéias para a concepção de softwares educativos, para que instruções e conteúdos apresentados em uma tela possam ser visualizados com facilidade, deve-se organizar seus itens em uma ordem que reflita a importância relativa de cada um.

Também é importante deixar uma quantidade razoável de espaços vazios, evitando a sobrecarga cognitiva. Experimentos mostram a maior parte dos usuários percebe a densidade de uma página da mesma maneira, sendo que o excesso de elementos reduz a performance na busca de informações (Wardeiner, 2007).

O alinhamento consistente dos itens em uma tela (blocos de texto, colunas, checkboxes, botões de rádio, etc) também facilita a leitura. Um alinhamento mal feito causa movimentos excessivos do olho, na medida em que não há nenhum percurso óbvio a ser seguido, como mostra o exemplo da figura 1.

\section{Google Quiz}

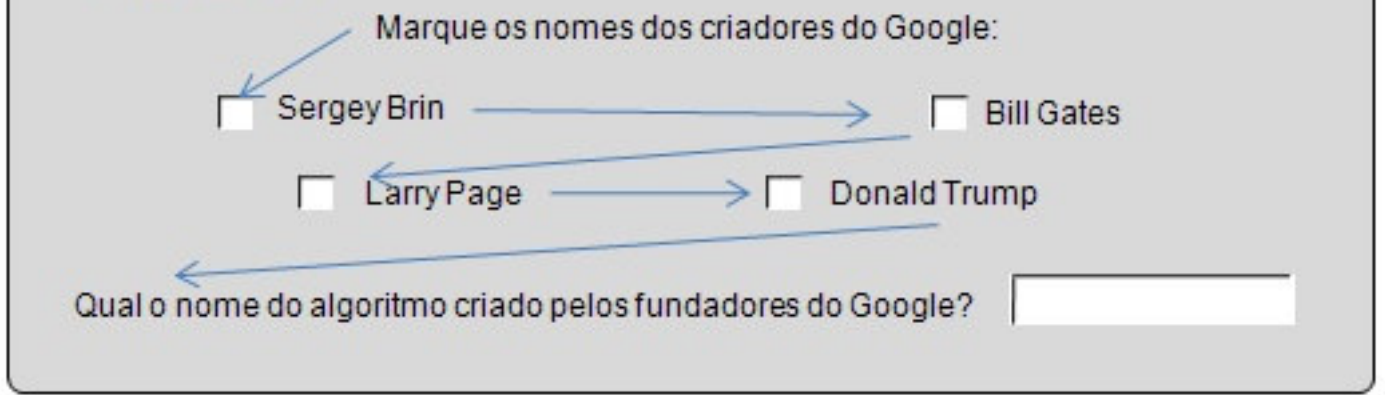

Figura 2. Formulário com mau alinhamento de rótulos e campos

Através do alinhamento de rótulos e de campos, os movimentos do olho são minimizados, facilitando o percurso e a busca de informações. 


\section{Google Quiz}

Marque os nomes dos criadores do Google:

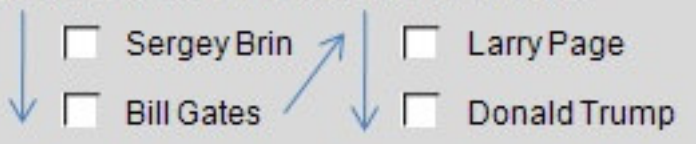

Qual o nome do algoritmo criado pelos fundadores do Google?

$\downarrow \longdiv { }$

Figura 3. Formulário com bom alinhamento de rótulos e campos

Apesar de possuírem a mesma densidade relativa, é mais fácil encontrar dados no último formulário (figura 3), dado que suas informações estão estruturadas visualmente de maneira lógica.

\section{Orientação e Navegação}

Da mesma forma que podemos nos sentir perdidos quando circulamos em um local desconhecido, também podemos nos sentir desorientados ao utilizarmos um sistema computacional - causando-nos uma sensação de insegurança e gerando uma série de questões recorrentes: Onde estou? Que atividades já realizei? Quais os próximos passos? Como posso retornar?

Um bom sistema de orientação provê respostas a estas questões o tempo todo, sinalizando os caminhos percorridos pelo usuário e indicando com clareza outros disponíveis.

Estas características são particularmente importantes quando tratamos de hipertextos, os quais põem em cheque a narrativa linear e oferecem múltiplas possibilidades de leitura em percursos alternativos (Landow, 1992). Desde sua criação, os hipertextos adquiriram grande importância no contexto da educação, possibilitando uma forma de leitura e de escrita mais próximas do nosso próprio esquema mental (Ramal, 2002). A estruturação dos textos com múltiplas conexões trouxe novas possibilidades de interação com o usuário, permitindo que cada um escolhesse seu caminho na teia de associações disponível, construindo seu próprio conhecimento a partir de seus interesses.

Neste universo no qual cada usuário define seu percurso dinamicamente, um sistema eficiente de orientação é fundamental. Um dos mecanismos de orientação mais simples e mais importante é o título. Além de enfatizar a porção do sistema na qual o usuário se encontra, títulos bem redigidos e visualmente claros permitem que o usuário encontre conteúdos mais rapidamente (Bailey et al., 2007). Também é possível orientar o usuário através de sistemas de cores, análogos aos mecanismos utilizados para orientar usuários no mundo real, como em redes de metrô, ônibus, etc (Thissen, 2004). Nestes, cada linha possui uma cor que é utilizada na sinalização de todas as estações pelas quais a linha passa. Em sistemas computacionais, o mesmo é possível, atribuindo-se cores diferentes a seções distintas do sistema.

Igualmente relevantes são os mecanismos de navegação, que permitem ao usuário se deslocar de um ponto a outro em um website ou hipertexto. Uma das principais 
estruturas de navegação são os hiperlinks. Por isso, é importante empregarmos convenções sedimentadas para identificação destes, como a utilização da cor azul para links textuais ainda não percorridos, e vermelho/roxo para links já percorridos. Além da cor, o uso do formato sublinhado também denota a presença de um hiperlink. A combinação das duas convenções (cores e formatação) reforça ainda mais a identificação do hiperlink.

Mecanismos de orientação e navegação eficazes permitem que os estudantes mantenham seu foco nos objetos de estudo e não precisem despender nenhum esforço para se localizar no software ou aprender a utilizá-lo.

\section{Interação}

Quando conversamos com pessoas, utilizamos palavras, expressões faciais e linguagem do corpo para nos comunicarmos. Através destes recursos de comunicação, somos capazes de expressar tanto idéias quanto sentimentos. Com o computador, não podemos nos comunicar através destes mesmos mecanismos. Ao invés deles, empregamos dispositivos de entrada e saída que estabelecem outros paradigmas de comunicação e estilos de interação (PREECE et al., 2002).

Um software educativo concebido com bases construtivistas, certamente tem na interação um dos seus principais focos. Projetos de softwares com esta perspectiva apóiam as práticas pedagógicas com relação à autonomia do sujeito e à forma de trabalhar o erro (COSTA, 2005). Com base nesta abordagem, os alunos constroem seu conhecimento a partir de suas próprias experiências e a partir de auto-regulações que ocorrem através das relações estabelecidas entre o sujeito e o objeto (Piaget, 1973).

Giraffa e Viccari (1998) classificam os softwares para apoio pedagógico em quatro categorias:

- Exercício: exercita conteúdos (estilo acertos/erros);

- Tutorial: apresenta conteúdos de forma dirigida;

- Simulação e modelagem: permite a visualização de situações reais;

- Jogo educativo: proporciona uma fonte de recreação com vistas à aquisição de um determinado tipo de aprendizagem;

Dentre estas, as categorias de simulação e de jogos são as que normalmente promovem maior interação com o usuário. No entanto, para desfrutar dos benefícios destes recursos interativos, é fundamental conceber adequadamente os processos de comunicação entre homem e máquina (Tognazzini 2003), empregando mecanismos que promovam o pensamento e a reflexão, e vão além da simples seleção de hiperlinks para avançar ou retornar na apresentação dos conteúdos.

\section{Usabilidade}

A usabilidade mede a qualidade da experiência de um usuário quando interage com um produto ou sistema. Em geral, a usabilidade se refere à facilidade que os usuários têm em aprender a utilizar um produto para alcançar seus objetivos, e o quão satisfeitos ficam com o processo. Steve Krug (2006), por exemplo, mostra como a falta de usabilidade pode afetar negativamente a utilização de um produto. Em relação aos 
softwares educativos, problemas na usabilidade da interface podem não apenas dificultar o uso do sistema quanto prejudicar a aprendizagem dos conteúdos.

Wardeiner (2007) aponta cinco fatores para medir a usabilidade de uma interface:

- Facilidade de aprendizagem: avalia o quão rápido um usuário que nunca viu uma interface anteriormente pode aprendê-la suficientemente para realizar tarefas básicas.

- Eficiência de uso: verifica o quão rápido usuários experientes podem realizar suas tarefas.

- Memorização: avalia se um usuário que já utilizou o sistema consegue lembrar-se dele para utilizá-lo efetivamente uma próxima vez.

- Freqüência de erro e severidade: mede o quão seguido o usuário comete erros quando utiliza o sistema e o quão sério são estes.

- Satisfação subjetiva: avalia o quanto o usuário gosta de utilizar o sistema.

A maior parte destes fatores está relacionada a algum dos tópicos já apresentados no artigo. Por exemplo, a facilidade de aprendizagem está relacionada aos mecanismos de orientação e navegação empregados. A eficiência de uso e freqüência de erros estão relacionadas principalmente aos mecanismos de interação utilizados, enquanto a memorização pode estar vinculada à densidade de informação existentes nas telas (layout). Já a satisfação subjetiva está ligada principalmente a fatores como estética e afetividade, aspectos comentados na próxima seção.

\section{Estética e Afetividade}

Emoção e motivação são forças centrais por trás de atos humanos. A pesquisa na área de motivação assume que esta está presente no desempenho de todas as atividades, ou seja, um comportamento aprendido não ocorrerá a não ser que seja "energizado" (Huitt, 2001). Por esta razão, um bom software educativo explora não apenas o lado cognitivo, mas também o lado afetivo, e utiliza estratégias de motivação específicas.

O apelo estético de uma interface pode motivar um usuário a utilizar determinado sistema. Pesquisadores na área de fatores humanos demonstraram também que a estética pode afetar usabilidade aparente de uma interface (Korosu \& Kashimura, 1995; Tractinsky, 1997) - ou seja, pode influenciar a percepção do usuário quanto à facilidade de uso do sistema. Donald Norman, que demonstrou porque a forma de utilização de um produto nunca deveria ser confusa (Norman, 2002), em obra mais recente argumenta que a pesquisa em emoção e cognição tem comprovado que objetos atrativos funcionam melhor, na medida em que as pessoas têm mais disposição para utilizá-los (Norman, 2004).

Outros pesquisadores argumentam que, nos últimos anos, muitas evidências foram encontradas apontando que cognição e afetividade juntas guiam o comportamento racional, a busca de fatos na memória, a criatividade e a tomada de decisão (Picard et al., 2004). Tais pesquisas enfatizam a necessidade de se desenvolver teorias e tecnologias nas quais cognição e afetividade sejam integradas de modo apropriado.

Uma forma eficaz de se trabalhar afetividade em um sistema computacional é através de agentes de interface animados, personagens virtuais capazes de perceber os estados afetivos do usuário e reagir a estes de maneira apropriada. Vários pesquisadores têm 
investigado o impacto destes personagens em sistemas computacionais aplicados à educação. Craig et al. (2002) mostraram que a interação com personagens estáticos e animados podem afetar a aprendizagem dos estudantes. Outros experimentos demonstraram que a presença da figura humana tem um efeito positivo nas experiências interativas dos estudantes, mostrando que estudantes consideraram um tópico em estudo menos difícil e a apresentação mais lúdica na presença de um personagem virtual (André e Rist, 2002).

\section{Considerações finais}

É comum que as interfaces dos softwares educativos sejam desenvolvidas com o simples propósito de operar e controlar um sistema, sem considerar implicações pedagógicas envolvidas no design de cada um dos seus componentes. Este trabalho apresentou como empregar adequadamente diversos recursos na concepção de interfaces para softwares educativos, de maneira a promover construção do conhecimento. Aspectos importantes no design de interface foram abordados, como usabilidade, interação, afetividade, entre outros.

Dado o caráter multidisciplinar do desenvolvimento de softwares educativos, no qual profissionais das mais diversas áreas devem interagir, torna-se de extrema importância a utilização de diretrizes específicas para o design das interfaces, normas fundamentadas em princípios pedagógicos e direcionadas à promoção da aprendizagem.

\section{Referências}

ANDRÉ, E. \& RIST, T. (2002). From adaptive hypertext to personalized web companions. Communications of the ACM, v45 n5, May.

APARICI, R. e GARCÍA-MATILLA, A. (1998). Lectura de Imágenes. Madrid: Ediciones de la Torre.

BAILEY, R. W. et al. (2007). Research-Based Web Design \& Usability Guidelines. U.S. Department of Health and Human Services. Disponível em:

http://www.usability.gov/pdfs

COSTA, L. A. C. e FRANCO, S. R. K. Ambientes Virtuais De Aprendizagem e suas Possibilidades Construtivistas. Revista Novas Tecnologias na Educação, v. 3, n. 1. Maio, 2005.

CRAIG, S., GHOLSON, B. e DRISCOLL, D. (2002). Animated Pedagogical Agents in Multimedia Educational Environments. Journal of Educational Psychology, Vol. 94, No. 2, 428-434.

GIRAFFA, L. M., VICCARI, R. M. (1998). Estratégias de Ensino em Sistemas Tutores Inteligentes modelados através da tecnologia de agentes. SBIE - Simpósio Brasileiro de Informática na Educação, Fortaleza: UFCE/SBC. v.1. p.260-269.

HUITT, W. (2001). Motivation to learn: An overview. Educational Psychology Interactive. Valdosta, GA: Valdosta State University. Disponível em: http://chiron.valdosta.edu/whuitt/col/motivation/motivate.html 
KOROSU, M., e KASHIMURA, K. (1995). Apparent Usability vs. Inherent Usability: Experimental Analysis on the Determinants of the Apparent Usability. Conference Companinon on Human Factors in Computing Systems. Denver, Colorado.

KRUG, S. (2005). Don't Make Me Think: A Common Sense Approach to Web Usability (2nd Edition). New Riders Press, 2005.

LANDOW, G. P. (1992). Hypertext: The Convergence of Comtemporay Critical theory and Tecnology. Baltimore and London: The John Hopkins Universty Press.

MAYER, R. (2001). Multimedia Learning. New York, NY: Cambridge University Press. cap. 4.

MAYER, R. E. e ANDERSON, R. B. (1991). Animations need narrations: An experimental test of a dual-coding hypothesis. Journal of Educational Psychology, 83, 484-490.

MORRISON, J. B. e TVERSKY, B. (2001). The (In)Effectiveness of Animation in Instruction. CHI 2001 - Conference on Human Factors in Computing Systems, ACM Press. Short Talk. Seattle, USA, 31 March-5 April.

NIELSEN, J. (1997). How users read on the web. Alertbox, October, 1. Disponível em: http://www.useit.com/alterbox/9710a.html

NIELSEN, J. e TAHIR, M. (2002). Homepage Usability: 50 Websites Deconstructed. Indianapolis, IN, USA: New Riders Publishing.

NIELSEN, J. (2003). The Ten Most Violated Homepage Design Guidelines. Alertbox, November 10, 2003. Disponível em: http://www.useit.com/alertbox/20031110.html

NORMAN, D. A. (2002). The Design of Everyday Things. New York, NY: Basic Books.

NORMAN, D. A. (2004). Emotional Design: Why we love (or hate) everyday things. New York, NY: Basic Books.

PIAGET, J. (1973). Estudos Sociológicos. Rio de Janeiro: Forense. 243p.

PICARD, R. W., PAPERT, S., BENDER, W., BLUMBERG, B., BREAZEAL, C., CAVAllO, D., MACHOVER, T., RESNICK, M., ROY, D., STROHECKER, C. Affective Learning: A manifesto. BT Technology Journal, Vol 22, No 4. October 2004

PREECE, J., ROGERS, Y., SHARP, H. (2005). Design de Interação. Além da Interação Humano-Computador. Porto Alegre, RS: Bookman.

RAMAL, A. C. Educação na Cibercultura: Hipertextualidade, Leitura, Escrita e Aprendizagem. Porto Alegre: ArtMed, 2002.

RESNICK, M. (2002). Rethinking Learning in the Digital Age. Disponível em: http://www.cid.harvard.edu/cr/pdf/gitrr2002_ch03.pdf

SHIMADA, H. e KITAJIMA, M. (2006). Why Do Illustrations Promote Text Comprehension? Motivation Effect and Elaboration Effect. 5th International Conference of the Cognitive Science. Vancouver, British Columbia, Canadá, July 26.

THISSEN, F. (2004). Screen Design Manural: Communicating Effectively through Multimedia. Berlin: Springer Verlag.

TOGNAZZINI, B. (2003). First Principles of Interaction Design. AskTog / Nielsen and Norman Group. Disponível em: 
http://www.asktog.com/basics/firstPrinciples.html

TVERSKY, B. (2007). What makes visualization effective? Disponível em: http://visual.nlm.nih.gov/evc/meetings/vrc2004/position_papers/tversky.pdf

WARDEINER, M. R. (2007). Usability Engineering Team: Design Guidelines. NASA Glen Research Center. Disponível em:

http://www.grc.nasa.gov/WWW/usability/navigatecss.html

THALHEIMER, W. Another Guru Sharing the Same Old Myth. Will at Work Learning. December, 20. Disponível em:

http://www.willatworklearning.com/myths_and_worse/index.html

TRACTINSKY, N. (1997). Aesthetics and apparent usability: empirically assessing cultural and methodological issues. Proceedings of the SIGCHI conference on Human factors in computing systems. Atlanta, Georgia, United States. pp.115 - 122. 